Revista Universo Contábil, ISSN 1809-3337

Blumenau, v. 9, n. 3, p. 38-54, jul./set., 2013

doi:10.4270/ruc.2013321

Disponível em www.furb.br/universocontabil

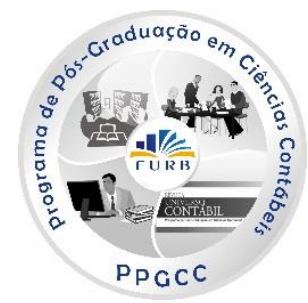

PROVISÕES, CONTINGÊNCIAS E O PRONUNCIAMENTO CPC 25: AS PERCEPÇÕES DOS PROTAGONISTAS ENVOLVIDOS 1

\title{
PROVISIONS, CONTINGENCIES AND CPC 25 REMARKS : THE PERCEPTIONS OF THE ACTORS INVOLVED
}

\section{PROVISIONES, RIESGOS Y OBSERVACIONES 25 CPC: LAS PERCEPCIONES DE LOS ACTORES INVOLUCRADOS}

\author{
Antônio de Cístolo Ribeiro \\ Mestre em Controladoria e Contabilidade pela FEA-USP \\ Professor na Faculdade de Economia, Administração e Contabilidade de \\ Ribeirão Preto da Universidade de São Paulo - FEA-RP/USP \\ Endereço: Rua Prudente de Morais 1170/34 \\ CEP 14040-905 - Ribeirão Preto - SP \\ E-mail: cistolo@hotmail.com \\ Telefone: (16) 8825-6862 \\ Maisa de Souza Ribeiro \\ Doutora em Controladoria e Contabilidade pela Universidade de São Paulo \\ Professora na Faculdade de Economia, Administração e Contabilidade de \\ Ribeirão Preto da Universidade de São Paulo - FEA-RP/USP \\ Endereço: Avenida dos Bandeirantes, 3900 \\ CEP 14040-905 - Ribeirão Preto - SP \\ E-mail: maisorib@usp.br \\ Telefone: (16) 3602-4747 \\ Elionor Farah JreigeWeffort \\ Doutora em Controladoria e Contabilidade pela FEA-USP \\ Professora na FECAP - Fundação Escola de Comércio Álvares Penteado \\ Endereço: Rua Pedroso Alvarenga 263/171 \\ CEP 04531-011 - São Paulo - SP \\ E-mail: eweffort@fecap.br \\ Telefone: (11) 3272-2301
}

\footnotetext{
1 Artigo recebido em 29.09.2012 Revisado por pares em 30.04.2013. Reformulado em 12.09.2013. Recomendado para publicação em 16.09.2013 por Carlos Eduardo Facin Lavarda. Publicado em 30.09.2013. Organização responsável pelo periódico: FURB.
} 


\section{RESUMO}

Com a introdução das normas contábeis do International Financial Reporting Standards (IFRS) no Brasil pelo Comitê de Pronunciamentos Contábeis (CPC) a partir de 2008, comobrigatoriedade de reportar as informações contábeis seguindo os novos procedimentos a partir de 31 de dezembro de 2010, abriu-se um novo horizonte para a prática contábil em nosso país e a convergência às normas internacionais de contabilidade. As novas normas versam, entre outros aspectos, sobre o reconhecimento de passivos e ativos com base no grau de probabilidade de ocorrência, requerendo, portanto, uso de julgamento por profissionais envolvidos. Este artigo é resultado de uma pesquisa científica, que estudou mais especificamente o contencioso legal tributário e a percepção de advogados, auditores e juristas sobre a introdução do pronunciamento CPC 25 que trata da contabilização de provisões, ativos e passivos contingentes no Brasil e a possibilidade de prática de Gerenciamento de Resultados com uso de provisões sobre contencioso legal. Recorreu-se a parecer de juristas da área de direito tributário (Martins e Carrazza) para esclarecer aspectos de singularidade e subjetividade do sistema tributário brasileiro. No decorrer da pesquisa, ficou evidenciado que a aplicação do referido pronunciamento é uma questão interdisciplinar, uma vez que envolve no processo, o parecer de consultores jurídicos, auditores e contadores. Foi também evidenciado que a prática de gerenciamento de resultado contábil (GR) pode ser reduzida quando existem boas práticas de governança corporativa. A pesquisa, realizada de 2009 a 2011, é de natureza qualitativa com a coleta de dados primários gerados por entrevistas à profissionais de auditoria e de direito.

Palavras-chave: Gerenciamento de Resultados. Provisão. Ativo Contingente. Passivo Contingente. Contencioso Legal Tributário.

\section{ABSTRACT}

With the introduction of the International Financial Reporting Standards (IFRS) in Brazil, the Accounting Pronouncements Committee (CPC) issued a so called CPC 25 that addresses as from 2008, with mandatory reporting accounting information following the new procedures as of December 31, 2010, the rules for accounting for provisions, contingent assets and liabilities in Brazil, it was opened a new horizon for the accounting practice in our country and finally reached the expected convergence of accounting standards. The new rules deal with, among other things, on the recognition of assets and liabilities based on the degree of probability of occurrence. It requires, therefore, use of judgment of professional involved. It was intended that the level of subjectivity involved to be reduced based on reports issued by independent and specialized experts. This article is a result of a scientific research, with addressed more specifically the tax law and litigation. It was analyzed the perceptions of lawyers from large offices that support companies, auditors and lawyers jurists professors and authors recognized in the area of tax law, on introduction of CPC 25 and the possibility of practice management results with the use of provision for litigation legal in Brazil. It was appealed to opinion of the jurists (Martins and Carrazza) to clarify aspects of subjectivity and singularity of the Brazilian tax system. During the research, it became evident that although this matter is regulated by the issuing agency CPC Accounting Standards, it is an interdisciplinary issue, since it involves the process, the opinion of legal counsel, auditors and accountants. It was also evident that the practice of earnings management $(G R)$ can be reduced when there is good corporate management in place. The research was qualitative with the primary data collection in interviews with legal and auditing professionals.

Keywords: Earnings Management. Provision. Contingent Asset. Contingent Liability. Tax Litigation. 


\section{RESUMEN}

Con la introducción de las normas contables del International Financial Reporting Standards (IFRS) en Brasil, por medio del Comité de Pronunciamientos Contables (CPC) desde 2008, y con la obligatoriedad de reportar las informaciones contables siguiendo los nuevos procedimientos desde el 31 de diciembre de 2010, se abrió un nuevo horizonte para la práctica contable en nuestro país y la convergencia con las normas internacionales de contabilidad. Las nuevas normas recogen, entre otros aspectos, el reconocimiento de pasivos y activos en base al grado de probabilidad de ocurrencia, debiéndose, por lo tanto, recurrir a la evaluación por parte de los profesionales involucrados. Este artículo es el resultado de una investigación científica, en la que se ha estudiado más específicamente el contencioso legal tributario y el análisis de abogados, auditores y juristas sobre la introducción del pronunciamiento CPC 25 que trata sobre la contabilización de provisiones, activos y pasivos contingentes en Brasil y la posibilidad de Práctica de Administración de Resultados con uso de provisiones sobre el contencioso legal. Se recurrió al parecer de juristas de derecho tributario (Martins e Carrazza) para aclarar aspectos de singularidad y subjetividad del sistema tributario brasileño. A lo largo del estudio, quedó patente que la aplicación del pronunciamiento indicado es una materia interdisciplinar, ya que incluye en el proceso el parecer de consultores jurídicos, auditores y contables. Igualmente, quedó patente que la práctica de la administración de resultado contable $(G R)$ puede reducirse cuando existen buenas prácticas de gobernanza corporativa. El estudio, realizado entre los años 2009 y 2011, es de naturaleza cualitativa en lo que se refiere a la recopilación de datos primarios generados por entrevistas a profesionales del campo de la auditoría y el derecho.

Palabras clave: Administración de Resultados. Provisión. activo Contingente. Pasivo Contingente. Contencioso Legal Tributario.

\section{INTRODUÇÃO}

As provisões são componentes importantes de um sistema contábil e se prestam a atender ao regime de competência dos fatos ocorridos, diferenciando-se do regime de caixa que depende da entrada ou saída de recursos de recursos financeiros. Exemplificando, se uma despesa é contabilizada a débito de resultado no momento em que é paga pela entidade, significa que está sendo contabilizada pelo regime de caixa. Ao se fazer o referido registro contábil no período em que há o consumo do recurso, independente da data do pagamento, tem-se o regime de competência e esta é a prática contábil correta uma vez que contrapõe despesas e receitas dentro do período a que efetivamente se referem em termos de realização. Embora, algumas das grandes empresas já procurassem antecipar as mudanças contábeis, principalmente aquelas com negociações no exterior e, também apesar do fato de o Brasil contar uma legislação societária relativamente atualizada, a influência da legislação fiscal sobre as empresas brasileiras sempre foi muito grande. Assim, antes da introdução das normas do IFRS no Brasil, a contabilidade prestava-se, em muitos casos, principalmente a atender critérios de dedutibilidade fiscal e por isso mesmo as provisões eram estabelecidas para atender critérios impostos pela legislação tributária e normas da receita federal. Após a introdução das normas do IFRS, as provisões e as contingências tanto ativas como passivas tiveram sua contabilização disciplinada pelo Pronunciamento Técnico CPC 25 - Provisões, Passivos Contingentes E Ativos Contingentes, aprovado em 26 de junho de 2009 (CPC 25) .

O Comitê de Pronunciamentos Contábeis - CPC 25, correlato do InternationalAccounting Standard, IAS 37, que trata da contabilização de provisões e divulgação de ativos e passivos contingentes e determina que a decisão de constituir provisões para contingências tributárias ou legais ou apenas divulgá-las deve ser embasada em laudos de 
experts. A possibilidade de se tomar decisões discricionárias em situações que sejam de interesse dos gestores pode facilitar a prática de gerenciamento de resultado (GR).

As novas normas são mais exigentes em relação à contabilização das provisões e divulgação dos passivos contingentes, exigindo que as empresas se adaptem para atendê-las. De acordo com instrução do CPC, uma provisão deve ser contabilizada sempre que uma operação passada ou atual, fora das condições de normalidade e não embasadas em contratos ou emissão de nota fiscal, possa gerar desembolsos de caixa futuros para uma companhia, desde que haja possibilidade de se mensurar o valor deste desembolso. Quanto ao desembolso de caixa futuro, para que a provisão seja constituída, deve ser mais provável que ocorra do que não ocorra este desembolso. O valor do desembolso deve ser possível de ser calculado. Se estas exigências não forem cumpridas, a empresa não constitui provisão, mas relata o fato em notas explicativas como passivo contingente. $\mathrm{O}$ julgamento da empresa sobre a possibilidade de ocorrer, ou não, desembolsos de caixa futuros vai depender de documentação interna existente e no caso de contencioso tributário, de laudo emitido pelos seus advogados onde se apure valores, prazos e probabilidade de ocorrência destes eventos.A verificação final e aprovação dos valores com base nas evidências internas são feitas pelas empresas de auditoria externa. Como nas várias fases de determinação dos valores, prazos e probabilidades de ocorrência, os agentes envolvidos devem tomar decisões subjetivas quanto a constituir uma provisão ou a divulgar um passivo contingente em notas explicativas, o processo torna-se muito subjetivo e pode levar a práticas de gerenciamento contábil. Gerenciamento contábil neste contexto é usar de subjetividades existentes e fazer escolhas contábeis para se alcançar um resultado desejado.

O GR é uma prática contábil que pode decorrer de motivos que vão da tentativa de se distribuir mais uniformemente os resultados anuais, até a defesa de interesses particulares de gerentes e diretores, quando os mesmos são remunerados com base nos resultados alcançados.

Este artigo é resultado de uma pesquisa científica, que estudou mais especificamente o contencioso legal tributário e analisou a percepção de advogados de grandes escritórios que dão suporte a empresas, auditores e juristas sobrea introdução do pronunciamento CPC 25 que trata da contabilização de provisões, ativos e passivos contingentes no Brasil e a possibilidade de prática de Gerenciamento de Resultados com uso de provisões sobre contencioso legal no Brasil.

\section{REVISÃO DA LITERATURA}

\subsection{Pesquisa sobre Gerenciamento de resultado}

Em análise da literatura internacional, pode-se verificar que as práticas de gerenciamento de resultados (GR) estão relacionadas com provisões para créditos de liquidação duvidosa, (McNICHOLS e WILSON 1988); depreciações (DeAngelo,1988); e antecipação ou postergação de reconhecimento de receita ou equalização (Smoothing) da receita (DEFOND e PARK, 1997). Para consolidar a fundamentação teórica, tem-se que buscar ainda os escritos sobre GR, como o conceito de "creative accounting" ou contabilidade criativa, assim definida por Griffiths (1986) que explora o referido conceito dando uma conotação de manipulação de resultados e considera que contadores podem manipular valores que divulgam.

No Brasil vários artigos foram publicados sobre práticas de GR. Martinez (2001) estudou as companhias abertas brasileiras no período de 1995 a 1999 e constatou que elas praticam GR, com objetivos de evitar reportar perdas, sustentar o desempenho recente e reduzir a variabilidade dos resultados. Lopes e Tukamoto (2007) analisaram as companhias listadas em bolsa no período de 1995 a 2003, verificando GR em função da norma contábil adotada, eles estudaram práticas de GR com aplicação das normas Norte Americanas 
(USGAAP), IASC e Alemãs (GGAAP), concluindo que a prática de GR independe da norma adotada. Paulo, Martins e Corrar (2007) estudaram o GR por meio de imposto de renda diferido, comparando as práticas no Brasil e nos Estados Unidos.

Coelho e Lopes (2007) examinaram a existência de GR nas companhias abertas brasileiras. A hipótese investigada foi a de que as escolhas contábeis são baseadas em produzir informações adequadas aos objetivos econômicos dos gestores e proprietários. Nardi et al (2009 p.2) concluíram que "certas escolhas são feitas para iludir os usuários quanto ao real desempenho econômico-financeiro da companhia por meio de GR, o qual seria fruto de uma atitude oportunista". Segundo eles, "se tal fato é possível, pode-se verificar que o objetivo de reduzir a assimetria informacional e contribuir para a alocação de recursos mais segura, por parte da contabilidade, pode não ser alcançado". Cardoso et al (2006) investigaram se a intensidade de acumulações discricionárias é diferente para empresas cujo nível de governança corporativa é certificado pela BM\&FBovespa, comparativamente àquelas que não o são; e para as empresas cujas ações negociadas na BM\&FBovespa têm alto nível de liquidez comparadas àquelas cujos títulos têm baixa liquidez. Os autores constataram em estudos empíricos que não é estatisticamente significante na amostra de 1701 observações feitas entre 1997 e 2004, a intensidade de acumulação discricionária entre os grupos estudados. Martinez (2006) investigou se as empresas gerenciam seus resultados com o propósito de reduzir sua variabilidade. O período investigado foi de 1995 a 1999 e os dados coletados do sistema Economatica ${ }^{\circledR}$. O estudo apurou que a redução da variabilidade dos resultados é um fator condicionante na decisão do reconhecimento de despesas. Os métodos de alocação de custos podem estar sendo estrategicamente definidos para influenciar o resultado contábil.

\subsection{Teoria da Agência}

O estudo da agência é importante para este trabalho, à medida que fornece uma sustentação teórica, para se entender os motivos que levariam um gerente a praticar o gerenciamento de resultados. Quando não estiver defendendo seus interesses particulares, o gerente poderá estar agindo coercivamente no interesse do principal, sendo que esta coerção pode ser declarada, ou por próprias limitações criadas pelo agente, em defesa, por exemplo, de seu emprego.

Jensen e Meckling (1976) ao tratarem da teoria da agência afirmam que o principal, ao contratar um agente para agir em seu interesse, dá inicio a uma relação de conflito entre os seus desejos e os do agente contratado, ambos podem ter comportamentos totalmente diferentes frente ao risco. O principal vai arcar com um custo extra parasupervisionar e controlar as ações do agente. $\mathrm{O}$ agente por estar envolvido nas operações diárias de uma entidade, com muito mais detalhes, acaba adquirindo uma carga de informações que muitas vezes não chegam até ao principal, dando então origem a assimetrias de informações. Berle e Means (1932) analisaram a composição, evolução da corporação e a divergência de interesses entre propriedade e controle.

\subsection{Contexto geral da legislação tributária brasileira}

Como esta pesquisa envolveu provisões, contingências e o parecer do assessor jurídico para tomada de decisão sobre a necessidade de se contabilizar, ou não, foi necessário se fazer uma ponte entre a contabilidade e o direito e entender as variáveis do processo de tomada de decisão sobre probabilidades de perda e ganho de processos e valores envolvidos. Assim, os advogados aparecem juntamente com os auditores entrevistados como protagonistas deste estudo. O Brasil passou até os anos 80 por um período de altas taxas inflacionárias que obrigava o governo a emitir periodicamente os chamados pacotes econômicos, que eram medidas de ajuste na economia, tentando baixar as taxas de inflação e que geralmente traziam 
consigo, várias leis de ajuste fiscal que tentavam aumentar a arrecadação, com objetivo de equilibrar as contas públicas. Muitas leis eram depois contestadas quanto à sua constitucionalidade, o que acabou gerando disputas judiciais e criando obrigações ao governo de indenizar contribuintes por leis inconstitucionais. Comentando a importância da constitucionalidade da lei tributária, Carrazza explica:

Todos os artigos da lei maior que tratam, direta ou indiretamente, da ação estatal de tributar só encontram sua real dimensão se conjugados com os princípios magnos de nosso sistema constitucional. As normas infraconstitucionais, maiormente as tributárias, para terem validade devem passar pelo crivo dos princípios constitucionais. Assim, o contribuinte somente estará sujeito à lei tributária quando esta for coerente com o conteúdo material dos grandes princípios que encontram morada na Constituição. (CARRAZZA, 2010, p. 54).

Não obstante a norma constitucional, as tentativas de emitir leis que ferem a constituição, no Brasil são frequentes, por isso o contribuinte deve resguardar na justiça os seus direitos. Conforme Sadek (2008):

Desde a Constituição Federal de 1988, 3994 leis foram questionadas no Supremo Tribunal Federal (STF). Neste período, 200 leis foram invalidadas no STF. No ano de 2007 das 128 normas estaduais e federais analisadas pelo STF 103 foram consideradas inconstitucionais. Para se ter uma ideia no México no período de 1994 a 2002, apenas foram questionadas 600 leis, sendo que 21 foram consideradas inconstitucionais. Em toda a história dos Estados Unidos, apenas 35 leis federais não estão mais em vigor por causa de vícios na sua elaboração Sadek (2008).

Ainda, conforme Sadek (2008), existem 235 mil normas tributárias brasileiras, de acordo com pesquisa doInstituto Brasileiro de Planejamento Tributário (IBPT). Sadeck informa que:

Por conta das normas, as empresas brasileiras são as que gastam mais tempo por ano com burocracia fiscal, segundo pesquisa também do Banco Mundial, são mais de 2600 horas ou 108 dias por ano gastos com obrigações tributárias municipais, estaduais e federais. Enquanto isso, empresas da Nova Zelândia ou da Suíça gastam em torno de 70 horas por ano Sadek (2008).

Foi comentado por um dos advogados entrevistados, que a qualidade da legislação tributária brasileira tem melhorado e que hoje já não são emitidas tantas normas inconstitucionais como em um passado recente, quando na ânsia de aumentar a arrecadação eram emitidas normas que levavam a administração tributária e as empresas a intermináveis disputas judiciais e alegação de inconstitucionalidade de leis.

O Brasil tem, conforme informação divulgada no site "Portal Tributário" 85 diferentes impostos, taxas e contribuições de melhoria, que são aplicados alguns a todas as empresas e outras a ramos de negócio ou operações especificas. O gerenciamento e cumprimento de todas as referidas normas devem ser bastante complexos, pois além do número grande de tributos existentes, cada um se veste de uma rotina especial e de obrigações acessórias que se não cumpridas levam a multas e processos administrativos e judiciais.

O tributarista, pesquisador e professor livre docente, Martins que trabalha na área tributária há mais de 50 anos, enfatiza a complexidade da legislação tributária no Brasil: 
O sistema é caótico, particularmente à luz das sucessivas emendas constitucionais, que o maltrataram, com superposições de incidências e elevado nível de complexidade. Gera um custo fantástico de administração para contribuintes e para os diversos erários, facilitando a sonegação dolosa e impondo, para muitos setores a inadimplência sobrevivencial, como forma de sobreviver à falência. (MARTINS, 2008)

Este emaranhado de leis sobrepostas dificulta o bom andamento das empresas. Existe um desperdício de tempo e trabalho profissional por parte do governo para revisar processos passados. O tributarista discute a premência de uma reforma tributária para a economia brasileira, afirmando que:

Não obstante às dificuldades enfrentadas, o futuro da economia brasileira não prescinde de uma profunda reforma que seja capaz de remover os entraves que $\mathrm{o}$ atual regime tributário brasileiro erige à melhoria $\mathrm{e}$ sustentação da competitividade da produção brasileira no mercado global. O grau de dificuldade dessa tarefa cresce à medida que, como ocorre no Brasil, o caminho da modernização tributária passa por penosas negociações federativas que se processam sob a ótica de preocupações imediatas com o impacto de quaisquer propostas de mudanças sobre os respectivos orçamentos. (MARTINS, 2008).

Mediante esta complexa teia de decretos e leis estaduais, municipais e federais os investidores, principalmente, internacionais podem se sentir temerosos de investirem no país, e, nesse sentido, a convergência das normas contábeis para normas internacionais poderá contribuir para aumento da confiança de investidores.

\section{METODOLOGIA}

A pesquisa foi qualitativa, exploratória e triangulou informações colhidas em entrevistas realizadas no período de junho de 2011 a março de 2012, com advogados e auditores, explorando a existência e o mecanismo de gerenciamento de resultados por meio do contencioso legal tributário seguindo o esquema da ilustração 1. A alguns dos advogados entrevistados foi atribuída a denominação de juristas, por militarem como professores, serem autores reconhecidos na área de direito tributário. A seleção dos entrevistados deu-se pelo critério de saturação.

Para fundamentar alguns dos dados qualitativos colhidos, foi efetuada análise de dados quantitativos do banco de dados da Economatica ${ }^{\circledR}$ e do banco de dados da BM\&FBovespa, que serviu de suporte à interpretação das informações qualitativas.

Neste estudo foi explorada a possibilidade de ocorrência de um fenômeno específico da área contábil, com forte interação com o mundo jurídico, mas que também é guiado por variáveis comportamentais.

\section{Ilustração 1 - Esquema do trabalho de pesquisa}

\begin{tabular}{|l|l|l|}
\hline Análise Exploratória & $-->$ & Advogado/auditor/5 empresas \\
\hline Análise de conteúdo & $-->$ & $\begin{array}{c}\text { Notas explicativas de } 3 \\
\text { Empresas da BM\&F - Bovespa }\end{array}$ \\
\hline Pesquisa documental & $--->$ & Normas Legais \\
\hline Pesquisa em base de dados secundários & $--->$ & Economatica \\
\hline Entrevistas - Fase 1 & $--->$ & 3 auditores e 3 advogados \\
\hline Entrevistas - Fase 2 & $--->$ & 3 auditores e 3 advogados \\
\hline Consulta a Especialistas & $--->$ & 2 tributaristas (Juristas) \\
\hline
\end{tabular}

Fonte: Ilustração dos autores 
Não se pretendeu neste trabalho gerar dados replicáveis, mas explorar o fenômeno em estudo e as possibilidades de ocorrência do mesmo, por isso o suporte na teoria da agência que entre outras variáveis explica o comportamento do principal e do agente numa relação. Assim, o foco principal desta pesquisa é gerar entendimento do problema,

Os conceitos usados para avaliação de pesquisa quantitativa não são de aplicação generalisada, embora frequentemente usados em toda espécie de pesquisa. Conceitos de qualidade relevantes para pesquisa quantitativa com propósito de explicar são discutidos como se eles fossem relevantes mesmo quando um estudo qualitativo tem prpósito de gerar entendimento. (STENBACKA 2001, p. 551) ${ }^{\mathrm{i}}$

A pesquisa se justificou, por evidenciar possibilidade de práticas de GR via provisões legais, sendo esta é uma característica peculiar do Brasil, devido à complexidade da legislação. A divulgação de alguns mecanismos de GR contribuirá para a redução de assimetrias de informações entre os vários agentes e para demonstrar algumas fragilidades das normas.

\section{ANÁLISE DAS ENTREVISTAS}

Os quadro 1e 2 refletem dados colhidos em entrevistas com auditores e advogados. Estes quadros demonstram que a percepção dos profissionais de advocacia e de auditoria ainda não é consensual, entretanto, instrumentos relevantes para melhor interface com a complexa legislação tributária brasileira foram mencionados, tais como governança, controles internos, treinamentos entre outros. Na sequência cada uma das categorias de comentários será analisada.

\subsection{Implantação do IFRS no Brasil}

A opinião de advogados e auditores sobre a implantação do IFRS no Brasil varia desde afirmar que os benefícios trazidos pela padronização das normas atrairão investimentos para o país, até à necessidade de treinamento dos contadores para se adaptarem às novas normas. Os contadores estavam acostumados com normas objetivas e devem aprender a trabalhar com a subjetividade das normas do IFRS. Houve também observação de que a introdução do IFRS foi uma ótima chance que as companhias tiveram para sanearem seus balanços.

A resposta dos advogados foi vaga, pois na prática não estão acostumados a considerar o efeito contábil dos laudos dentro das empresas. Os auditores profissionalmente lidam no dia a dia com as mudanças de práticas contábeis e a influência destas mudanças nos resultados das entidades. 
Quadro 1 - Análise de Conteúdo de entrevistas - Auditores

\begin{tabular}{|c|c|c|c|}
\hline & \multicolumn{3}{|c|}{ Auditores } \\
\hline Questões & AUD 1 & AUD 2 & AUD 3 \\
\hline $\begin{array}{l}\text { Implantação } \\
\text { IFRS }\end{array}$ & $\begin{array}{l}\text { Atração para investimentos } \\
\text { estrangeiros. A base não } \\
\text { foi preparada (treinamento } \\
\text { dos profissionais) IFRS } \\
\text { pressupõe subjetividade } \\
\text { responsável. }\end{array}$ & $\begin{array}{l}\text { Não tiveram grandes } \\
\text { problemas com a implantação } \\
\text { em seus clientes. }\end{array}$ & $\begin{array}{lcr}\text { Empresas } & \text { ajustaram } & \text { os } \\
\text { balanços } & \text { aproveitando } & \text { a } \\
\text { introdução do IFRS. } & \end{array}$ \\
\hline $\begin{array}{l}\text { Gerenciament } \\
\text { o de } \\
\text { Resultados } \\
\text { (GR }\end{array}$ & $\begin{array}{l}\text { O brasileiro continuará } \\
\text { achando um jeito de levar } \\
\text { vantagem onde a norma } \\
\text { permitir. GR é incentivado } \\
\text { por situação financeira } \\
\text { ruim. Se o negócio estiver } \\
\text { em risco pode haver caso } \\
\text { de GR. }\end{array}$ & $\begin{array}{l}\text { Conta provisões é cheia de } \\
\text { subjetividades. Legislação } \\
\text { complexa. Possibilidade de } \\
\text { GR altíssima. }\end{array}$ & $\begin{array}{l}\text { Pode ser feito por: } \\
\text { interpretações subjetivas, } \\
\text { escolhas contábeis, fraudes. } \\
\text { Difícil delimitar fronteira do } \\
\text { ético e não ético }\end{array}$ \\
\hline $\begin{array}{l}\text { Provisões } \\
\text { para } \\
\text { contingências } \\
\text { no } \\
\text { Brasil } \\
\end{array}$ & Não opinou & Manter Valores Corrigidos. & $\begin{array}{l}\text { Altos valores. Nível } \\
\text { Subjetividade. Complexidade } \\
\text { da legislação. }\end{array}$ \\
\hline $\begin{array}{l}\text { Notas } \\
\text { explicativas }\end{array}$ & Maior transparência. & $\begin{array}{l}\text { Muito importante divulgar o } \\
\text { movimento. Evitar divulgar o } \\
\text { efeito líquido. }\end{array}$ & $\begin{array}{l}\text { Divulgação cobre lacunas. } \\
\text { Importante mostrar detalhes } \\
\text { da movimentação. }\end{array}$ \\
\hline $\begin{array}{l}\text { Ressalvar } \\
\text { Parecer }\end{array}$ & Não opinou & Não opinou & $\begin{array}{l}\text { Em casos extremos após } \\
\text { esgotar discussões o auditor } \\
\text { pode ressalvar o parecer das } \\
\text { DFs. }\end{array}$ \\
\hline $\begin{array}{l}\text { Relatório dos } \\
\text { Advogados }\end{array}$ & Não opinou & $\begin{array}{l}\text { O relatório dos advogados tem } \\
\text { influência contábil. Seria bom } \\
\text { estabelecer um procedimento } \\
\text { em relação aosrelatórios. }\end{array}$ & $\begin{array}{l}\text { O auditor é cético, o advogado } \\
\text { não. O advogado deve estimar } \\
\text { a chance de ganho ou perda } \\
\text { dos processos. O auditor } \\
\text { analisa o relatório e julga o } \\
\text { mérito de acordo com sua } \\
\text { experiência. O auditor discute } \\
\text { o relatório. }\end{array}$ \\
\hline $\begin{array}{l}\text { Complexidade } \\
\text { Legal }\end{array}$ & Não opinou & $\begin{array}{l}\text { Prevalece à forma sobre a } \\
\text { essência. A complexidade está } \\
\text { no número de processos, na } \\
\text { possibilidade de recursos. } \\
\text { Legislação por medidas } \\
\text { provisórias. } \\
\text { Órgãos federais legislam por } \\
\text { instrução normativa. Depois } \\
\text { vai tudo para o supremo } \\
\text { tribunal para julgar se a } \\
\text { medida é válida ou não. }\end{array}$ & $\begin{array}{l}\text { Refis para evitar problema } \\
\text { estrutural. Volume de } \\
\text { processos. O mal pagador é } \\
\text { privilegiado em detrimento } \\
\text { bom pagador. É necessária } \\
\text { uma reforma tributária. }\end{array}$ \\
\hline $\begin{array}{l}\text { Prevenção do } \\
\text { GR }\end{array}$ & $\begin{array}{l}\text { Controles internos. } \\
\text { Práticas de governança. } \\
\text { Deve existir ética. }\end{array}$ & $\begin{array}{l}\text { Evitar contingências ativas. } \\
\text { Foco na Governança. } \\
\text { Conselho Independente. }\end{array}$ & Governança \\
\hline
\end{tabular}


Quadro 2 - Análise de conteúdo de entrevistas - Advogados

\begin{tabular}{|c|c|c|c|}
\hline Questões & ADV 1 & ADV 2 & ADV 3 \\
\hline Implantação IFRS & Não opinou & $\begin{array}{l}\text { Acho que terá um resultado } \\
\text { muito significativo dentro das } \\
\text { companhias }\end{array}$ & Não opinou \\
\hline $\begin{array}{l}\text { Gerenciamento de } \\
\text { Resultados. }\end{array}$ & Não opinou & Não Opinou & $\begin{array}{l}\text { É possível pela complexidade } \\
\text { das leis }\end{array}$ \\
\hline $\begin{array}{l}\text { Provisões para } \\
\text { contingências no } \\
\text { Brasil. }\end{array}$ & Não opinou & Não opinou & $\begin{array}{l}\text { Probabilidade estabelecida } \\
\text { pelo advogado. Contabilização } \\
\text { assumida pela administração. } \\
\text { Validadas pelos auditores. } \\
\text { Subjetividade na definição. }\end{array}$ \\
\hline Notas explicativas & $\begin{array}{l}\text { Reduz assimetrias de } \\
\text { informações. }\end{array}$ & Não opinou & Não opinou \\
\hline $\begin{array}{l}\text { Relatório dos } \\
\text { Advogados e } \\
\text { influência } \\
\text { Contábil. } \\
\text { Procedimento } \\
\text { em relação } \\
\text { aos } \\
\text { relatórios. }\end{array}$ & $\begin{array}{l}\text { O grau de chance de } \\
\text { perda ou sucesso é } \\
\text { estipulado, analisando } \\
\text { o processo em si, os } \\
\text { códigos legais e } \\
\text { pesquisa nos tribunais } \\
\text { para ver as } \\
\text { jurisprudências } \\
\text { existentes.. Antes de } \\
\text { emitir o laudo } \\
\text { algumas companhias } \\
\text { exigem que seja } \\
\text { discutido com seu } \\
\text { departamento } \\
\text { jurídico. } \\
\text { Somos criteriosos } \\
\text { para passar os valores } \\
\text { mais próximos da } \\
\text { realidade. Se o } \\
\text { advogado emite laudo } \\
\text { fora da realidade pode } \\
\text { ser que haja alguma } \\
\text { responsabilidade legal } \\
\text { sim. }\end{array}$ & $\begin{array}{l}\text { Relatórios na periodicidade } \\
\text { pedida pelo cliente. Os } \\
\text { relatórios consideram a } \\
\text { demora do judiciário. } \\
\text { Estimativa de prazo para o } \\
\text { processo. Separam por esfera } \\
\text { e consideram chance de ganho } \\
\text { ou perda por esfera. O critério } \\
\text { para definir probabilidade de } \\
\text { ganho ou perda são as } \\
\text { decisões mais atuais e as } \\
\text { tendências dos tribunais.. Nos } \\
\text { países desenvolvidos a } \\
\text { legislação não dá margem para } \\
\text { discussões. Os relatórios são } \\
\text { discutidos com as companhias } \\
\text { no momento de se contratar o } \\
\text { trabalho ou entrar com uma } \\
\text { ação. Depois só discute } \\
\text { novamente se mudarem as } \\
\text { condições. Valores fixados de } \\
\text { acordo com tabelas emitidas } \\
\text { pelos tribunais. Tratamento } \\
\text { contábil deve ser discutido } \\
\text { entre as companhias de } \\
\text { auditores. }\end{array}$ & $\begin{array}{l}\text { O relatório é a base para se } \\
\text { constituir provisões. } \\
\text { As leis mudam muito e podem } \\
\text { provocar mudanças nos } \\
\text { relatórios }\end{array}$ \\
\hline $\begin{array}{l}\text { Complexidade } \\
\text { Legal. }\end{array}$ & $\begin{array}{l}\text { A lei é muito } \\
\text { subjetiva. } \\
\text { Dá margem a várias } \\
\text { interpretações. }\end{array}$ & $\begin{array}{l}\text { Sistema tributário é complexo. } \\
\text { Legislação interpretativa leva } \\
\text { a subjetividades. } \\
\text { Observou-se melhoria na } \\
\text { elaboração das leis. Legislador } \\
\text { tem melhorado a qualidade } \\
\text { das leis. . }\end{array}$ & $\begin{array}{l}\text { As leis são complexas e } \\
\text { mudam muito. Difícil alguém } \\
\text { se manter atualizado sobre as } \\
\text { exigências fiscais e tributárias. }\end{array}$ \\
\hline Prevenção do GR. & Não opinou & $\begin{array}{l}\text { Manipulações devem } \\
\text { diminuir: } \\
\text { Lei } 11638 \text { e acompanhamento } \\
\text { rígido dos órgãos de controle. }\end{array}$ & $\begin{array}{l}\text { Controles internos e } \\
\text { personalidade do contador. }\end{array}$ \\
\hline
\end{tabular}

Fonte: Dados gerados em entrevistas

\subsection{Gerenciamento de Resultados}

Ao exercerem sua profissão, os contadores se deparam com uma "área cinzenta" da legislação, onde é possível que se faça escolhas contábeis. Como o GR é uma prática não 
declarada pelos praticantes, comentar sobre GR envolve opiniões e percepções. Neste campo a não opinião dos advogados, que restringiram sua opinião à complexidade das leis que permitiria praticar o GR, demonstra que sua preocupação é emitir o laudo com base em suas interpretações das probabilidades de perdas ou ganho, deixando para a administração da entidade e a auditoria, decidir sobre a contabilização ou não dos valores.

Os auditores são mais críticos e consideram que o empresariado sempre procurar tirar vantagem de uma determinada situação. Como o IFRS não define normas rígidas, mas se guia por uma subjetividade responsável, a tendência será que se pratique GR quando a entidade se encontre em uma situação financeira crítica. Na percepção dos auditores entre as várias possibilidades de prática de GR, sobressaem as interpretações subjetivas e as escolhas contábeis e também a prática de fraudes, sendo difícil delimitar o que é ético ou não ético. A conta de provisões é cheia de subjetividades e a legislação complexa gera possibilidade altíssima de GR.

\subsection{Provisões para contingências no Brasil}

As percepções de advogados e auditores indicam preocupação com a subjetividade no estabelecimento das provisões, complexidade das leis e altos valores envolvidos. O Advogado3 entrevistado, tem uma visão bem realista e entende o papel do advogado como assessor e a responsabilidade da administração, ao estabelecer valores e contabilizar provisões.

Os auditores comentam que há altos níveis de provisões sobre o contencioso tributário no Brasil e isto é consequência da subjetividade e complexidade da legislação. Acharam que o IFRS deixou mais claro e prático a atribuição de probabilidade de perda ou ganho de uma ação ao usar a expressão "mais provável perder que ganhar" para se constituir a provisão (simplistamente, $49 \%$ perda VS $51 \%$ ganho); foi ressaltado que devem manter-se os valores provisionados corrigidos, e que isto pode ser uma fonte de subjetividades. Segundo informado por um dos auditores entrevistados. O Banco Central do Brasil exige que os Bancos pratiquem uma taxa fixa para estabelecer as provisões para créditos de liquidação duvidosa, no intuito de reduzir o risco sistêmico para os mesmos.

\subsection{Notas Explicativas}

Um dos auditores entrevistados afirmou que a divulgação de contingências em notas explicativas reduzirá assimetrias de informação; foi comentado ser muito importante para as companhias, pois poderá cobrir lacunas e eliminar erros de julgamentos. A informação fica transparente ao mercado e mesmo que mudem as possibilidades de perda ou ganho de processos, o mercado já estará ciente de sua existência. Um ponto visto como muito positivo foi a exigência de se divulgar a movimentação detalhada dasprovisões nas notas explicativas, mas alertou-se para se tomar cuidado para não divulgar somente o efeito líquido, o que prejudicará a transparência das demonstrações financeiras.

\subsection{Ressalvas em parecer relacionadas a provisões}

Perguntado sobre a possibilidade de ressalvar o parecer de um cliente por não concordar com os níveis de provisões, apenas um dos auditores respondeu e disse que para fazê-lo, o profissional deve estar bastante seguro e ter respaldo em documentação comprobatória. O melhor é discutir com o advogado do cliente e chegar a um acordo quanto à necessidade de se provisionar ou não. Embora a discussão possa parecer uma prática de GR, neste caso ela tem justamente o efeito contrário que é atribuir o grau mais provável de perda ou ganho do processo e decidir se contabiliza ou não a provisão. Neste caso, a discussão entre o auditor e o advogado, com a participação do cliente, ajuda a chegar a uma posição mais favorável, pela argumentação e pelo convencimento das partes. 


\subsection{Laudo (Relatório) dos advogados}

Um dos auditores afirmou que o auditor é cético e o advogado não. Como profissional da contabilidade o auditor estava fazendo menção ao princípio do conservadorismo. De acordo com este princípio as despesas devem ser antecipadas e as receitas postergadas. Mais uma vez aparece envolvida a percepção, quando o auditor diz que analisa o relatório de acordo com sua experiência. Mais uma vez aparece a inconstância da legislação, que pode levar a alterações em relatórios já emitidos. Importante notar que os advogados preferem usar a palavra "relatório" ao invés de "laudo" talvez para minimizar a carga de responsabilidade sobre o seu parecer.

Os relatórios são emitidos em periodicidade mensal ou de acordo com solicitação do cliente, afirmou um dos advogados. Os processos são separados por natureza e por esfera de julgamento sendo considerada a possibilidade de perda ou ganho em cada esfera. Esta possibilidade é determinada com base na experiência do profissional e na jurisprudência dos tribunais. Não há formato fixo sendo que cada advogado o emite de uma forma, dependendo da solicitação do cliente. Os critérios para atribuir probabilidade de ganho ou perda são por comparação com decisões mais recentes dos tribunais, usando da analogia.

As chances de perda ou ganho são discutidas com as companhias em um momento inicial e depois não se muda mais, a não ser que mudem as sinalizações vindas dos tribunais em relação à jurisprudência. Os valores são apurados de acordo com tabelas emitidas pelos tribunais. Os advogados não consideram os efeitos dos laudos que emitem nas demonstrações financeiras, a contabilização ou não dos valores deveser decidida entre a administração das companhias e seus auditores. Outro advogado entrevistado também expôs usar de analogia para definir chances de perda ou ganho, ele pesquisa os códigos legais e os tribunais, para verificar jurisprudências. Afirmou que discute os relatórios com algumas companhias antes de sua emissão e procura ser criterioso (subjetividade) para passar valores próximos da realidade. Este advogado admitiu que pudesse haver punição se for comprovado que o advogado emitiu laudo fora da realidade, ao mesmo tempo em que auditor considerou que a cultura brasileira não é severa na punição aos advogados.

Os auditores, por sua vez, afirmam que o advogado não possui domínio sobre os procedimentos contábeis, e que tal situação foi agravada com a introdução do CPC 25.É considerado que ainda há subjetividade no julgamento e que o instrumento ideal para julgamento é o histórico das companhias em relação à perda ou ganho de processos, quando esses existem. Um segundo auditor considera que o CPC 25, deixa mais claro o critério de avaliação da probabilidade de perda ou ganho dos processos e que costuma envolver especialistas do departamento jurídico da auditoria se discordar do advogado sobre algum caso constante do laudo. O terceiro auditor afirmou que analisa o relatório e faz julgamento de mérito de acordo com sua experiência e se não concordar com algum caso, discute o mesmo com o advogado. De forma geral, os profissionais do direito demonstram que agem de forma totalmente independente e que não se preocupam com a forma de uso ou consequências de seus relatórios.

Refletindo sobre o conjunto de respostas, podemos concluir que mesmo sendo verdade a afirmação feita por auditores de falta de conhecimento contábil por parte do advogado, desde que o advogado fundamente seu parecer de possibilidade de perda ou ganho dos processos em referencial jurídico consistente, ele estaria cumprindo efetivamente o seu papel, pois a decisão de contabilizar ou não uma provisão cabe à administração da companhia e neste caso, ela usaria como suporte o parecer do advogado.

\subsection{Complexidade das leis}

Advogados e auditores são unânimes ao enfatizarem a complexidade de nosso sistema tributário e ao fato de nossa legislação ser interpretativa. Foi comentado também que, a 
qualidade de nossas leis está melhorando e hoje não existe tantas leis inconstitucionais como existiu em tempos recentes e que deram origem a várias demandas que terminaram por serem julgadas pelo Supremo Tribunal Federal (STF). Foi observado por um dos auditores que o volume de processos sobre determinados temas acaba se transformando em problema estrutural e pressionando o governo que procura saídas alternativas como o financiamento de longo prazo a devedores como o Programa de Recuperação Fiscal (REFIS). Ele ressalta que o REFIS beneficia o mau pagador em detrimento de quem paga as obrigações em dia. Diz que há necessidade de reforma tributária para deixar o sistema mais claro e menos complexo. Também foi comentado que, no Brasil, em termos legais, ainda prevalece à forma sobre a essência. Há complexidade no número de processos e nas possibilidades de recursos. Todos os problemas do sistema acabam no judiciário para julgar a validade dos atos.

\subsection{Prevenção do GR}

Um dos auditores entrevistados opinou que as chances de GR são diminuídas pela lei e pela ação dos órgãos de controle. Entre os órgãos de controle no Brasil, ele elenca a Comissão de Valores Mobiliários (CVM), o Banco Central do Brasil (BCB), o Instituto Brasileiro de Contadores (IBRACON) e o próprio Conselho Regional de Contabilidade (CRC) com suas comissões de ética. Os auditores são unânimes em dizer que o GR pode ser prevenido pela boa governança. Dizem também que, deve existir ética, deve haver independência do conselho de administração e deve se tomar cuidado ao registrar contingências ativas.

As percepções dos profissionais entrevistados em geral refletem expectativas com melhoras a partir da introdução do IFRS. Os auditores em suas atividades cotidianas estão acostumados a analisarem e interpretarem os procedimentos da administração em função das regulamentações existentes. A complexidade da legislação dificulta aos advogados fazerem projeções estatísticas sobre possibilidade de perda ou ganho de um processo. Após estas rodadas de entrevistas ficaram algumas duvidas importantes para a consolidação do estudo, tais como qual a diferença do sistema legal brasileiro com o de outros países? Qual a singularidade de nosso sistema legal? Existe mesmo uma demora do judiciário em julgar os processos? Quanto a jurisprudência dos tribunais, existem mudanças frequentes, e como estas mudanças afetam o andamento dos processos? Estas questões seriam respondidas em nova rodada de entrevistas e a consulta efetuada com juristas.

\section{CONSULTA A JURISTAS}

Após as entrevistas com os auditores e advogados, ficaram dúvidas sobre as possíveis singularidades da legislação tributária brasileira, demora do judiciário, jurisprudência e complexidade da legislação. Como mencionado, o assunto é complexo, e, assim levou à decisão de solicitar a opinião de dois juristas, especialistas que militam na área do direito tributário, o Prof. Dr. Roque Antônio Carrazza e o Prof. Dr. Ives Gandra da Silva Martins (nomes citados com autorização dos entrevistados - consultados).

O jurista Martins dá um enfoque econômico financeiro e alega que não obstante a base constitucional, o sistema tributário brasileiro diferencia-se de outros países pelo excesso de burocracia, existem milhares de leis que criam obrigações principais e acessórias de difícil entendimento e aplicação às situações de fato pelos contribuintes. $\mathrm{O}$ tributarista atribui a complexidade existente à burocracia, à múltipla incidência de tributos sobre o mesmo fato gerador e à guerra fiscal entre os estados no caso do ICMS e os municípios, no caso do ISS.

Carrazza explica a singularidade de nosso sistema tributário pelo ponto de vista doutrinário e afirma que o que faz o sistema tributário brasileiro singular é que nossa legislação tributária é toda calcada no próprio texto constitucional, que já estabelece a autonomia tributária de cada ente federado e a forma de partição nas receitas. 
Comparando por exemplo a constituição brasileira com a italiana, enquanto a primeira é um compêndio completo de normas tributárias, a última inclui apenas duas normas que dão diretrizes gerais, sendo este um fator limitante ao legislador ao criar tributos. Uma das perguntas dirigidas ao Jurista foi quanto à possibilidade da jurisprudência sobre determinada questão jurídica mudar com o decorrer do tempo e a resposta dada com propriedade, afirma que sim e que esta mudança faz parte do desenvolvimento e do aperfeiçoamento do direito. Ao comentar sobre a morosidade do judiciário, o Jurista diz que realmente há um acúmulo de processos, mas que não se pode cobrar celeridade do judiciário em detrimento ao bom direito. Não se pode resolver rapidamente as questões jurídicas, deixando-se de fazer justiça e praticar o que o professor chama de "justiçamento".

Carrazza atribui a demora em se julgar os processos à administração pública que recorre até a última instância, mesmo quando já há jurisprudência clara sobre o julgamento de determinada questão. A respeito da complexidade de nossa legislação tributária, o professor observa que todos os sistemas tributários são complexos, esta não é uma característica exclusiva do sistema tributário brasileiro.

\section{CONSIDERAÇÕES FINAIS}

O CPC 25 ao mencionar a obrigação de se constituir ou não provisão, indica que em certos casos a empresa possa ser assistida por peritos ou peritos independentes. Como este estudo analisou as provisões constituídas em virtude de contingências legais, foi assumido que o advogado seria o profissional mais indicado para atuar como perito nestes casos, mas o CPC não atribui esta função especificamente ao advogado.

Os auditores comentaram em entrevistas que há altos níveis de provisões sobre o contencioso tributário no Brasil e isto é consequência da subjetividade e complexidade da legislação. Eles afirmaram que o IFRS deixou mais claro e prático a atribuição de probabilidade de perda ou ganho de uma ação ao usar a expressão "mais provável perder que ganhar" para se constituir a provisão (49\% perda VS 51\% ganho); foi ressaltado que devem manter-se os valores provisionados corrigidos, e que isto pode ser uma fonte de subjetividades. Os entrevistados também afirmaram que a divulgação de contingências em notas explicativas reduzirá assimetrias de informação; foi comentado ser muito importante para as companhias divulgarem informações em notas explicativas, pois este procedimento poderá cobrir lacunas e eliminar erros de julgamentos. A informação fica transparente ao mercado e mesmo que mudem as estimativas de possibilidades de perda ou ganho de processos, o mercado já estará ciente de sua existência. Um ponto visto como muito positivo foi a exigência de se divulgar a movimentação detalhada das provisões nas notas explicativas, mas alertou-se para se tomar cuidado para não divulgar somente o efeito líquido, o que prejudicará a transparência das demonstrações financeiras.

Analisando a exigência de se fazer um laudo para fundamentar a decisão de se constituir provisão, cabe perguntar o que poderia ser feito para eliminar as subjetividades existentes. $\mathrm{O}$ que gera subjetividade são as incertezas existentes no processo e que obrigam tanto o consultor legal como a administração da empresa a tomar decisões discricionárias. Detectou-se as seguintes fontes de incerteza; a) avaliação da probabilidade, b) morosidade dos processos administrativo e judiciário, c) fator humano, os quais são descritos a seguir:

a) Avaliação da Probabilidade

O CPC atribui ao perito, neste caso o advogado, a incumbência de estimar a probabilidade de se perder ou ganhar um processo. Além disso, o advogado deve estimar o valor provável de uma perda ou ganho. Estas duas variáveis são muito complexas e só podem ser apropriadamente dimensionadas por profissional experiente, com amplo conhecimento de andamento de processos tanto na esfera administrativa como na esfera judiciária. Na esfera administrativa, como os membros das comissões julgadoras são escolhidos pelo estado ou o 
estado exerce forte influência em sua indicação, a tendência é que sempre o contribuinte perca a ação. Devido a este fato, a atribuição de probabilidade tende a ser feita em relação a chance de sucesso ou perda na esfera judicial. Acontece que nenhum advogado entra com uma ação judicial pensando que irá perdê-la, a não ser por motivos de protelar o pagamento do valor em questão, o que já configuraria um gerenciamento de resultado. Um meio de minimizar as possibilidades de erro é a analogia com outros casos semelhantes, jurisprudência existente e também experiência anterior da empresa.

b) Morosidade dos processos administrativo e judiciário

Como comentado no item a, a tramitação na esfera administrativa é desconsiderada por ser tendenciosa, então cabe discutir a tramitação no judiciário. Conforme afirmou o Prof. Carrazza, a morosidade existente não é causada pelo judiciário em si, mas pelas muitas alternativas de recursos existentes e que são usadas indiscriminadamente pela administração pública. Paralelamente a isto, a interpretação dos juízes muda no decorrer do tempo e novamente o Prof. Carrazza ensina que isto faz parte do desenvolvimento do direito. No que pese ser positivo que o direito desenvolva as alterações sofridas na jurisprudência no decorrer do tempo de processo que pode ser de quatro anos na fase administrativa e de até 12 anos na fase gerencial, influenciarão na estimativa de perda e ganho feita pelos advogados e em última instância poderão causar constituição de provisão contábil ou provocar a reversão de provisões já constituída, com influência direta no resultado da entidade e na distribuição de dividendos aos acionistas.

\section{c) Fator Humano}

A emissão de laudo para embasar decisão que impacta direto no resultado da entidade exige maturidade profissional e firmeza pessoal por parte do profissional envolvido. Neste ponto a subjetividade pode estar relacionada à própria limitação pessoal do profissional. A experiência profissional adquirida e a vivência muito ajudarão a tomar decisão apropriada ao julgar possibilidade de perda e ganho bem como estipular o valor em risco. O profissional deve também contar com outros recursos, como consultas a tribunais e diálogo com colegas.

Referente a indícios da possibilidade de prática de GR via provisões relacionadas com o contencioso tributário legal, foi concluído que sim, é possível esta prática. Devido à complexidade da legislação tributária e a morosidade da justiça, o simples fato da empresa entrar com recurso contra autuação fiscal pode representar gerenciamento de resultados. Suponha-se que uma empresa esteja em ano de resultado negativo e que, além disso, receba auto de infração a normas tributárias. A empresa pode estar ciente que irá perder o recurso, pela causa do auto e pela fundamentação do fisco. Como o gestor sabe que se entrar com recurso administrativo poderá demorar até16 anos até ao final do processo, ele pode preferir entrar com recurso e esperar momento mais oportuno para provisionar a perda.

Com a implantação das normas do IFRS, houve padronização de procedimentos e aumento de exigências de disclosure informações em notas explicativas. $\mathrm{O}$ detalhamento das contas de provisões e suas movimentações são fortes aliados dos usuários contábeis por aumentarem a transparência e reduzirem assimetrias de informação. Enfim, a mitigação de práticas de GR se dará pelas práticas a serem desenvolvidas no dia a dia pelos contribuintes e reguladores das normas contábeis. Mesmo dentro de uma normatização subjetiva, é possível que se criem padrões que se apliquem a certas situações objetivas e que ao se desviar destes padrões as empresas devam fornecer explicações detalhadas sobre motivos e procedimentos.

\section{REFERÊNCIAS}

ALMEIDA, J. E. F. D.; COSTA, F. M. D.; LOPES, A. B.; TONIATO, J. B. Earnings management and industry classification in Brazil: an exploratory investigation. Corporate 
Ownership \& Control. v. 3, n. 1, 2005.

BAPTISTA, E. M. B.; MARTINEWSKI, A. L. Gerenciamento de resultados: revisão da literatura nacional e possibilidades de estudos futuros. IN: Congresso USP Controladoria e Contabilidade, 7., São Paulo/SP, 2007. Anais..., 2007.

BERLE, A.; MEANS, G. The Modern Corporation and Private Property. New York: MacMillan, 1932.

BRASIL, Senado Federal, Lei 6404, 1976.

, Comitê de Pronunciamentos Contábeis. Pronunciamento técnico CPC 25 - Provisões, Passivos Contingentes e Ativos Contingentes. Aprovado 26.06.2009. Disponível em: <http://www.cpc.org.br/mostraOrientacao.php?id=43> Acesso em 08.02.2011

CARDOSO et al. Acumulações Discricionárias, Liquidez e Governança Corporativa Divulgada no Brasil. In: Encontro da ANPAD, 30., 2006. Anais...Salvador, 2006.

CARRAZZA, R. A. Curso de Direito Constitucional Tributário. Malheiros Editores: São Paulo, 2010. p. 54. ISBN 978-85-7420-997-5

COELHO, A. C. D.; LOPES, A. B. Avaliação da Prática de Gerenciamento de Resultados na Apuração de Lucro por Companhias Abertas Brasileiras conforme seu Grau de Alavancagem Financeira. RAC, 2 ${ }^{\mathrm{a}}$ Edição Especial p.121-144.Rio de Janeiro/RJ, 2007.

DeANGELO, L.; Discussion of Evidence of Earnings Management from the Provision for Bad Debts. Journal of Accounting Research, v. 26, USA, 1988.

DeFOND, M. L.; PARK, C. W. Smoothing income in anticipation of future earnings. Journal of Accounting and Economics, v.23, p. 115-139, USA, 1997.

GRIFFITHS, I. Creative Accounting, London: Sidgwick \& Jackson, 1987. ISBN 0-04657003-9

JENSEN, M. C.; MECKLING, W. H. Theory of the firm: managerial behavior, agency costs of and ownership structure. Journal of Financial Economics. Rochester, n.3, p. 305-360, December, 1976.

LOPES, A. B.; TUKAMOTO, Y. S. Contribuição ao estudo do "gerenciamento" de resultados: uma comparação entre as companhias abertas brasileiras emissoras de ADRs e não emissoras de ADRS. R. ADM., v. 42, n.1, p.86-96, jan./fev./mar, 2007.

McNICHOLS, M.; WILSON, G. P. Evidence of Earnings Management from the Provision for Bad Debt. Journal of Accounting Research. v. 26. USA. 1988

MARTINS, I G. S.; CASTRO. P. R; MARTINS, R.V.G.S. Tributos no Brasil: Auge, Declínio e Reforma. Fecomércio, Brasil, 2008.

MARTINS, I G. S. Emaranhado tributário - Legislação existente é confusa, complexa e mal elaborado. Jornal Folha de S. Paulo, 23 de julho 2009. 
MARTINEZ A, L. "Gerenciamento" dos resultados contábeis: estudo empírico das companhias abertas brasileiras. 2001. 167 f. Tese (Doutorado em Ciências Contábeis) Departamentos de Contabilidade e Atuária, Faculdade de Economia, Administração e Contabilidade da Universidade de São Paulo. São Paulo, 2001.

, Minimizando a variabilidade dos resultados contábeis: estudo empírico do income smoothing no Brasil. Revista Universo Contábil, v. 2, n. 1, p. 09-25, Blumenau, jan./abr., 2006.

MATSUURA, L. Brasil é recordista em número de leis federais inconstitucionais. Consultor Jurídico, Junho 2008. Disponível em: http://www.conjur.com.br/2008-jun13/brasil_recordista_numero_leis_inconstitucionais acessado em 29.04.2012.

NARDI et al,. Gerenciamento de resultados e a relação com o custo da dívida das companhias brasileiras abertas. Revista Contabilidade e Finanças, Universidade de São Paulo- USP, v.20, 2009. DOI: http://dx.doi.org/10.1590/S1519-70772009000300006

PAULO, E.; MARTINS, E.; CORRAR, L. J. Detecção do gerenciamento de resultados pela análise do diferimento tributário. Revista de Administração de Empresas, vol. 47 nr.1, São Paulo, 2007. id=257119520005, ISSN 1519-7077

PORTAL TRIBUTÁRIO. Disponível em: <http://www.portaltributario.com.br/>.

RIBEIRO, A. C. Provisões, contingências e normas contábeis: um estudo de gerenciamento de resultados com contencioso legal no Brasil. Ribeirão Preto, 2012. 89 p. Dissertação (Mestrado) - Faculdade de Economia, Administração e Contabilidade de Ribeirão Preto/USP.

SADEK, M. T. Judiciário: mudanças e reformas. Estudos Avançados, São Paulo, v. 18, n. 51, p. 79-101, 2008. http://dx.doi.org/10.1590/S0104-44782013000100002

SEVIN, S.; SCHROEDER, R. Earnings Management: Evidence from SFAS No. 142 Reporting. Managerial Auditing Journal, v.1, n. 20, p. 47-54, 2005. http://dx.doi.org/10.1108/02686900510570696

STENBACKA, C. Qualitative research requires quality concepts of its own. Management Decision, v39, n.7, p551, 2001. http://dx.doi.org/10.1108/EUM0000000005801

\footnotetext{
i Tradução livre do original: The concepts used for evaluation of quantitative research are not generally applicable although most often used in all kinds of research. Quality concepts being relevant for quantitative research with a purpose of explaining were relevant even when a qualitative study has the purpose of generating understanding.
} 